\title{
Toll-like receptors in the pathogenesis of human B cell malignancies
}

\author{
Johana M Isaza-Correa, Zheng Liang, Anke van den Berg, Arjan Diepstra and Lydia Visser ${ }^{*}$
}

\begin{abstract}
Toll-like receptors (TLRs) are important players in B-cell activation, maturation and memory and may be involved in the pathogenesis of B-cell lymphomas. Accumulating studies show differential expression in this heterogeneous group of cancers. Stimulation with TLR specific ligands, or agonists of their ligands, leads to aberrant responses in the malignant B-cells. According to current data, TLRs can be implicated in malignant transformation, tumor progression and immune evasion processes. Most of the studies focused on multiple myeloma and chronic lymphocytic leukemia, but in the last decade the putative role of TLRs in other types of B-cell lymphomas has gained much interest. The aim of this review is to discuss recent findings on the role of TLRs in normal B cell functioning and their role in the pathogenesis of B-cell malignancies.
\end{abstract}

Toll-like receptors (TLRs) are essential receptors of the innate immune system and key regulators of the acquired immune system. Ten proteins (TLR1-10) have been identified in humans [1,2], each of them with a particular subcellular localization depending on the specific pathogen-associated molecular patterns (PAMPs) or damage-associated molecular patterns (DAMPs) they recognize (Table 1). TLR2 forms functional heterodimers with either TLR1 or TLR6. These heterodimers together with TLR4 and TLR5 are expressed on the cell membrane, whereas TLR3, TLR7, TLR8 and TLR9 are located in endosomes. TLRs induce pro-inflammatory molecules but, they are also implicated in proliferation, survival, and tissue repair [3].

TLRs are pattern recognition receptors structurally characterized by extracellular leucine rich repeats, and transmembrane and intracellular Toll/Interleukin-1 receptor (TIR) domains [1,3]. The extracellular domain interacts directly with PAMPs or DAMPs, triggering the downstream signaling through the TIR domain [1]. In mammals, four different types of signaling adaptor proteins can be recruited by the TIR domain: Myeloid differentiation primary-response protein 88 (MyD88), TIR-domain-containing adaptor protein inducing IFN $\beta$ (TRIF), TRIF-related adaptor molecule (TRAM),

\footnotetext{
* Correspondence: I.visser@umcg.nl

Department of Pathology and Medical Biology, University of Groningen, University Medical Center Groningen, Hanzeplein 1 HPC EA10, Groningen 9700RB, The Netherlands
}

and TIR-domain-containing adaptor protein (TIRAP) (Figure 1). The MyD88 signaling cascade is essential for TLR2, TLR4, TLR5, TLR7, TLR8 and TLR9. TIRAP activation is MyD88-dependent and is associated with TLR2 and TLR4. TRIF acts independently of MyD88 in signal transduction following TLR3 and TLR4 activation. TRAM mediates TLR4 signaling in a MyD88-independent/ TRIF-dependent way [1]. The adaptor proteins serve as a scaffold for the recruitment of IL-1R-associated kinases (IRAK) 1, 2, 4 and $\mathrm{M}$ and TAB2 and TNFreceptor-associated factor 6 (TRAF6) which eventually leads to nuclear translocation of Nuclear factor kappa-B (NF-kB) [1,3] (Figure 1). Other transcription factors that can be activated are activator protein 1 (AP-1) and interferon regulatory factor 3 (IRF3) [1].

The contribution of TLRs to B-cell lymphoma pathogenesis has gained more interest in recent years $[2,4]$, but it is not completely understood. This review summarizes the current knowledge on the expression of TLRs in normal B-cells and in B-cell malignancies and discusses how TLRs can contribute to onset and progression of these malignancies.

\section{Expression and function of TLRs in normal B-cells} Although expression of TLRs in normal B-cells is interesting, what happens in B-cells when they are triggered or the role they play in B-cell maturation and differentiation is more important. 
Table 1 Toll-like receptors (TLRs) and their DAMPs and PAMPs ligands

\begin{tabular}{|c|c|c|c|}
\hline & \multirow{2}{*}{$\begin{array}{l}\text { DAMPS (endogenous) } \\
\text { Ligand }\end{array}$} & \multicolumn{2}{|l|}{ PAMPs (exogenous) } \\
\hline & & Ligand & Origin \\
\hline \multirow[t]{2}{*}{ TLR1 } & & Tri-acylated Lipopeptides & Bacteria and Mycobacteria \\
\hline & & Soluble factors & Neisseria meningitidis \\
\hline \multirow[t]{10}{*}{ TLR2 } & HSP60, HSP70, HSP96 & Lipoprotein/lipopeptides & Various pathogens \\
\hline & HMGB1 & Peptidoglycan & Gram + bacteria \\
\hline & Hyaluronic acid & Lipoteichoic acid & Gram + bacteria \\
\hline & & Lipoarabinomannam & Mycobacteria \\
\hline & & Phenol-soluble modulin & Staphylococcus epidermis \\
\hline & & Glycoinostolphospholipids & Trypanosoma cruzi \\
\hline & & Glycolipids & Treponema maltophilum \\
\hline & & Porins & Neisseria \\
\hline & & Atypical-LPS & Leptospira interrogans and Porphyromonas gingivalis \\
\hline & & Zymosan & Fungi \\
\hline TLR3 & dsRNA, mRNA & dsRNA & Viruses \\
\hline \multirow[t]{8}{*}{ TLR4 } & HSP22, HSP60, HSP70, & LPS & Gram- bacteria \\
\hline & HSP96 & HSP60 & Chlamydia pneumonia \\
\hline & HMGB1 $\beta$-defensin 2 & Fusion protein & Respiratory syncytial virus \\
\hline & fibronectin & Envelope proteins & Mouse mammary tumor virus \\
\hline & Hyaluronic acid & Taxol & Plant product \\
\hline & Heparan sulphate & & \\
\hline & Fibrinogen & & \\
\hline & Surfactant-protA & & \\
\hline TLR5 & & Flagellin & Gram + or Gram- bacteria \\
\hline \multirow[t]{5}{*}{ TLR6 } & & Di-acylated lipopeptides & Mycoplasma \\
\hline & & Lipoteichoic acid & Gram + bacteria \\
\hline & & Zymosan & Fungi \\
\hline & & Phenol-soluble modulin & Staphylococcus epidermis \\
\hline & & Heat-liable soluble factor & Group B streptococcus \\
\hline TLR7 & Endogenous RNA & ssRNA & Viruses \\
\hline TLR8 & Endogenous RNA & ssRNA & Viruses \\
\hline \multirow[t]{2}{*}{ TLR9 } & Endogenous DNA & Unmethylated CpG motifs & Bacteria and viruses \\
\hline & & Hemozoin & Plasmodium \\
\hline TLR10 & Unknown & Unknown & \\
\hline
\end{tabular}

\section{TLR expression in B-cell subsets}

A number of studies investigated expression of TLRs in B-cell subsets isolated from peripheral blood mononuclear cells (PBMC) or tonsil. PBMC derived B-cells express TLR1, TLR6, TLR7, TLR9 and TLR10 [5]. Analysis of peripheral naïve and memory subsets indicates that only TLR1, TLR7 and TLR9 are expressed at low levels in naïve B-cells, while memory B-cells express high levels of TLR6, TLR7, TLR9 and TLR10 [6]. Tonsillar B-cells express less TLR7 than peripheral B-cells, but show higher TLR9 levels [7]. Bone marrow plasma cells express TLR1, TLR8 and TLR9 in a small subset of healthy controls [8].

\section{Triggering of TLRs in B-cells}

Triggering of resting or naive $\mathrm{B}$-cells through the $\mathrm{B}$-cell receptor (BCR), CD40 or CpG oligodesoxynucleotides (CpG) induces a quick upregulation of TLR7, TLR9 and TLR10 [6,9]. Triggering of TLR9 on PBMC derived B-cells with CpG induces its downregulation and in addition leads to an upregulation of TLR7 [5]. Bernasconi [6] hypothesized that low or null expression of TLRs in 


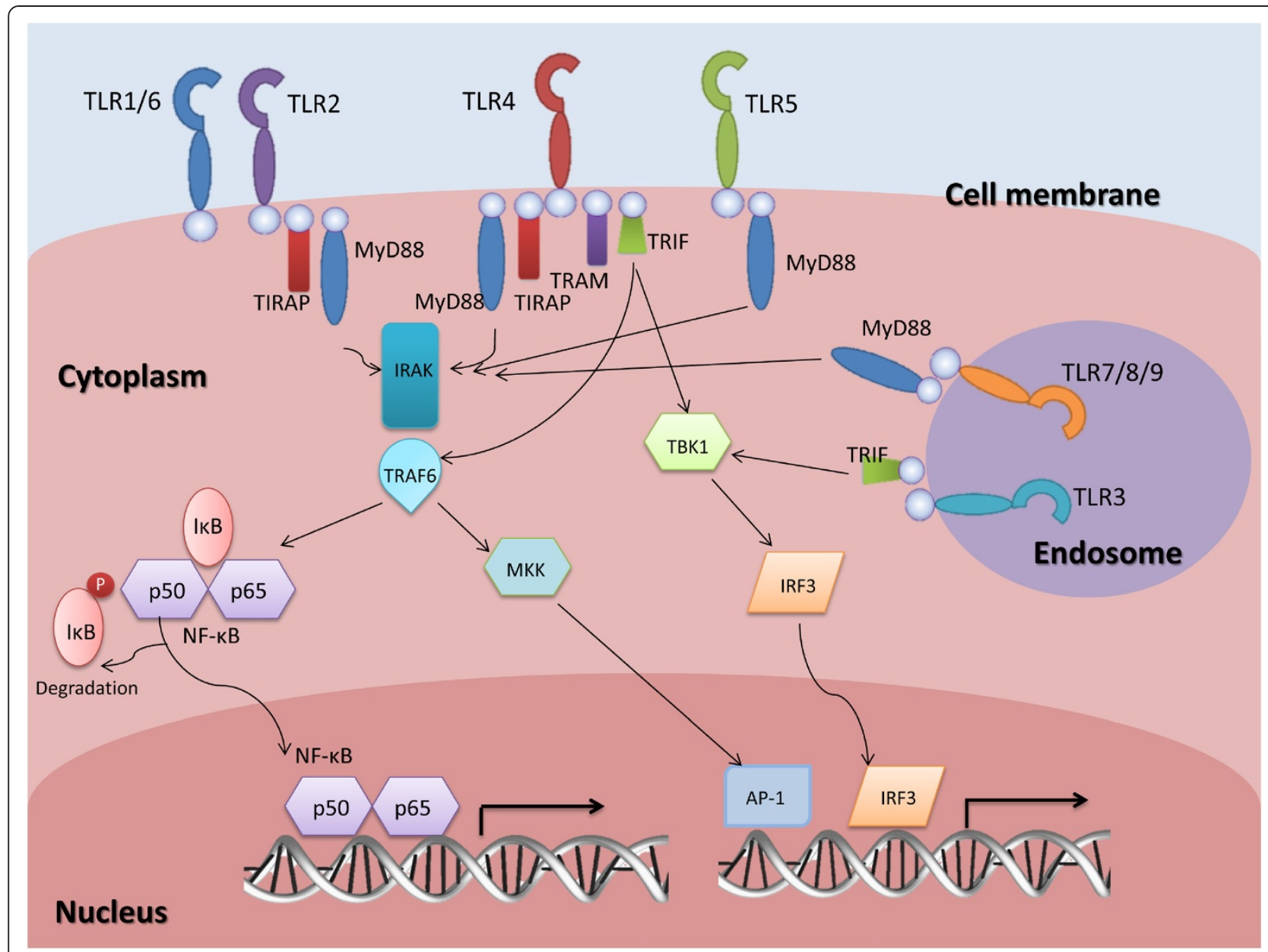

Figure 1 Signaling pathway of toll-like receptors (TLRs). After recognition of the ligand by the extracellular domain of TLRs, adaptor proteins are recruited to the TIR domain and initiate intracellular signaling. Four types of adaptor proteins have been identified in mammals: MyD88, TRIF, TRAM, and TIRAP. The recruitment of IRAK and TRAF6 to the adaptor proteins leads to nuclear translocation of NF-kB. TRAF6 can also activate MAPK kinases (MKK) leading to the activation of transcription factor AP-1. This pathway is common to all the TLRs, except for TLR3 which uses TANK-binding kinase 1 (TBK1) and results in the activation of IRF3.

naïve B-cells is a protective mechanism to avoid polyclonal activation. The high and diverse expression of TLRs in memory B-cells on the other hand, might facilitate continuous antibody production. Production of type I interferon (IFN) by plasmacytoid dendritic cells (pDCs) in response to infections positively modulates the expression of TLR7 but not of other TLRs in naïve B-cells [10].

Triggering of TLR1/TLR2, TLR7 and TLR9 in B-cells results in the upregulation of several B-cell activation markers, including HLA-DR, CD25, CD80 and CD86, as well as the production of several cytokines and chemokines $[7,11]$ (Figure 2). Cytokine production levels were higher in memory B-cells as compared to naïve B-cells, whereas chemokines are produced at similar levels [11].

\section{The role of TLRs in B-cell maturation and differentiation} Several studies showed that TLRs are involved in the formation of germinal centers (GC) (Figure 2). Stimulation of TLR2+ human B-cells, a small subpopulation found in blood or spleen, causes a GC like differentiation with upregulation of CD77 and production of CXCL13, CXCL8 and IL-6 [12]. In TLR7 deficient mice no GC B-cells are formed after immunization with Friend Virus [13], whereas in IL-21 $R^{\mathrm{ko}}$ mice, GC formation is dependent on the presence of TLR7 ligands [14].

Several studies demonstrate a crucial role of TLR triggering in the induction of class switch recombination (CSR). Stimulation of TLR4 with LPS can induce IgG2b CSR, while addition of IL-4 blocks this process [15]. CpG stimulation of TLR9 in the presence of MYD88, induces CSR to IgG2a, IgG2b and IgG3 in murine B-cells [16]. In human naïve (CD19+ CD27- IgG/A- ABCB1+) B-cells, TLR9 stimulation with $\mathrm{CpG}$ was required for CSR to IgG and IgA, in addition to BCR ligation and T-cell help [17]. T-cell independent stimulation of TLR9 with $\mathrm{CpG}$ in combination with IL-10 treatment of naïve 


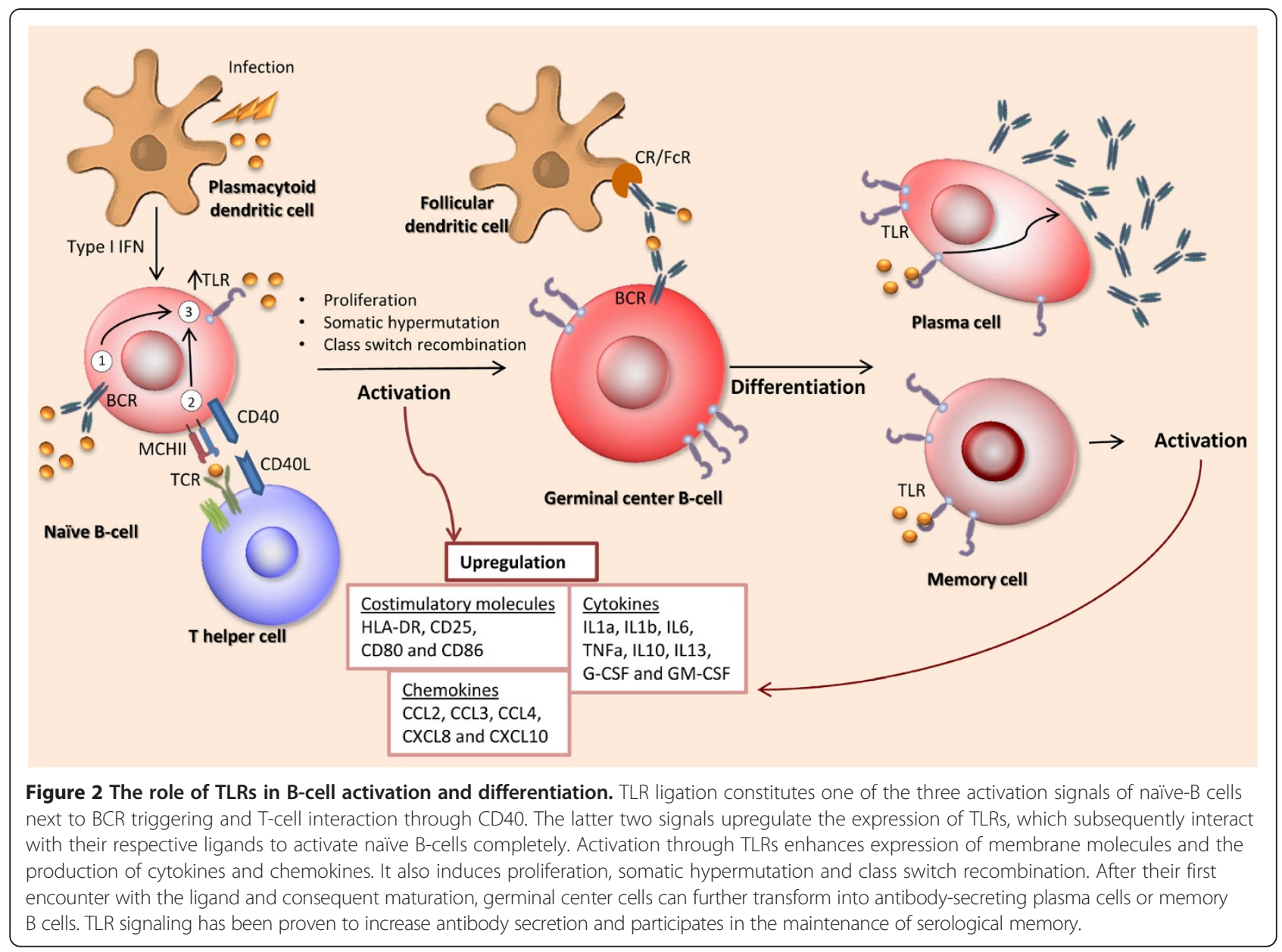

B-cells enhances expression of activation induced deaminase (AID) and the subsequent CSR to IgG1, IgG2, and IgG3 [18]. Upper respiratory mucosal B-cells can be stimulated with dsRNA via TLR3 and TRIF, to activate NF- $\mathrm{kB}$ and induce expression of AID and CSR to IgG and IgA [19]. BCR independent activation of murine resting B-cells via TLR2 and CD40 causes proliferation and differentiation to marginal zone precursor cells that have upregulated AID expression [20].

Somatically mutated memory B-cells can be generated from immature transitional B-cells upon CpG treatment. Most of the somatic hypermutations were observed in B cells containing VH1, VH4 and VH6 gene segments [21]. This study indicates that somatic hypermutation is dependent on or can be induced by TLR triggering.

Differentiation to plasma cells and the production of antibodies are two processes in which TLRs also play an important role (Figure 2). Several immunization studies in mice show that TLRs are essential for the production of antibodies. T-cell dependent immunizations in MyD88 KO mice do not lead to the production of antibodies, while triggering of TLR4 during the immunization procedure of wild type mice induces a significant increase in antibody titers [22]. Stimulation of TLR4 and TLR7 significantly enhanced antibody titers upon immunization [23]. Immunization with $\mathrm{CpG}$ linked to the protein antigen enhances B-cell proliferation and plasma cell differentiation [24]. For induction of an anti-viral response, MYD88 expression in B-cells was essential [13,25]. Naïve B-cells stimulated by $\mathrm{CpG}$ start proliferating and differentiate to IgM producing plasma cells with increased surface expression of molecules involved in antigen presentation such as HLA-DR, CD40 and CD80. These cells indeed have an increased potential to activate allogeneic T-cells [26]. Cord blood transitional B-cells express TLR9 and respond to CpG by expression of AID and BLIMP-1 and produce anti-pneumococcal antibodies as a first line defense at birth [27]. CpG stimulation of TLR9 positive IgM memory B cells drives differentiation to plasma cells that produce IgM antibodies to Streptococcus pneumoniae [27].

In summary, multiple studies show participation of TLRs in adaptive immunity, including modulation of the activation of B- and T-cells. In B-cells TLRs have been 
proposed to constitute the third essential signal for complete activation [17], along with BCR triggering and interaction with T-cells. Additionally, it has been shown that TLRs are involved in B-cell maturation by CSR, somatic hypermutation, induction and maintenance of GC and B-cell memory, differentiation to plasma cells and the production of antibodies. Considering the amount of evidence supporting TLR-MyD88 involvement in acquired immune responses mediated by B-cells, it is likely that they are involved in the pathogenesis of B-cell malignancies.

\section{TLR expression in B-cell malignancies}

B-cell malignancies are classified based on the resemblance of the tumor cells to specific maturation stages of normal B-cells, e.g. the normal counter part of follicular lymphoma (FL), Burkitt lymphoma (BL) and diffuse large B-cell lymphoma (DLBCL) are related to germinal center B-cells, while multiple myeloma (MM) is a plasma cell malignancy.

\section{Expression in multiple myeloma}

TLR1, TLR2, TLR3, TLR4, TLR7, TLR8, and TLR9 have been reported to be expressed in MM derived cell lines. Of these TLR1, TLR4, TLR7, and TLR9 are expressed most commonly [8,28]. Analysis of tumor cells from sorted bone marrow mononuclear cells of MM patients showed high TLR2, TLR4 and TLR9 mRNA levels and these findings were consistent with the high protein expression of TLR4 and TLR9 when analyzed by flowcytometry [29]. Overall, the expression of TLR4 and TLR9 is consistently reported in MM cell lines or primary cells.

\section{Expression in chronic lymphocytic leukemia (CLL)}

TLR1, TLR2, TLR6, TLR7, TLR9 and TLR10 were expressed in CLL, while the other TLRs were low or negative [30-32].

\section{Expression in other B-cell malignancies}

For other B-cell lymphoma types, studies on TLR expression are limited. In acute lymphoblastic leukemia (ALL) cell lines, TLR1, TLR2, TLR3, TLR4, TLR6 and TLR7 are expressed albeit at variable levels [33]. In bone marrow of ALL patients with $>90 \%$ blasts TLR2 mRNA can be detected in the majority of the samples [33]. BL cell lines express TLR7 and TLR9 [34]. Mucosa associated lymphoid tissue (MALT) lymphoma show strong expression of TLR4 and weak expression of TLR5 [35]. In mantle cell lymphoma (MCL), TLR1, TLR4, TLR7, TLR9 and TLR10 exhibit significant mRNA levels, whereas TLR2, TLR3, TLR5 and TLR8 are negative [36]. A significant expression of TLR2 and TLR8 at both the protein and mRNA level was found in DLBCL [37]. In comparison to reactive lymph node, TLR2 levels were high in DLBCL and TLR5 low in follicular lymphoma
(FL). TLR3, TLR6, TLR7 and TLR9 expression levels were similar in DLBCL, FL and peripheral $\mathrm{T}$ cell lymphoma [37].

Polymorphisms in TLRs have been shown to increase the risk of non-Hodgkin lymphoma [38], as well as in Hodgkin lymphoma [39-41].

Thus, it is evident that B-cell malignancies display a wide range of TLR expression patterns. Nevertheless, it remains to be elucidated if their expression resembles a normal B-cell phenotype or if it is a consequence of the malignant transformation.

\section{Potential role of TLRs in B-cell malignancies}

The survival and proliferative mechanisms used by malignant cells usually includes aberrant activation of signaling and regulatory pathways that are also used in their normal counterparts. Three possible pathogenic mechanisms can be anticipated for the TLRs which will be discussed below (See Figure 3).

\section{Role of TLRs in the transformation of normal B-cells into malignant B-cells}

One of the main indications that TLR are involved in the pathogenesis of B-cell malignancies comes from studies focusing on its adaptor protein MyD88. Knockdown of MyD88 in activated B cell type (ABC) DLBCL cell lines causes a marked decrease in proliferation, this effect was shown to be dependent on the presence of oncogenic mutations [42]. Specific oncogenic mutations in the Toll/IL-1 receptor (TIR) domain of MyD88 are found in $91 \%$ of lymphoplasmacytic lymphomas [43], $29 \%$ of ABC DLBCL, 9\% of gastric MALT lymphomas [42], 13\% of splenic marginal zone lymphomas (SMZL) [44], 2.9\% of CLL cases and 5.6\% of IgH-mutated CLL cases [45].

NF- $\mathrm{kB}$ is constitutively activated in various lymphoma subtypes and presents an important pathway to evade cell death. This is demonstrated by the frequent occurrence of somatic mutations in NF- $\kappa B$ related genes in mature B-cell lymphomas [46]. As NF-kB can be activated via triggering of the TLRs, this might provide a potential mechanism to avoid apoptosis and increase their proliferation rates. Consistent with this, triggering of TLR4 and TLR9 in MM resulted in nuclear translocation of NF-kB, and enhanced cell growth and IL-6 production [29]. In a similar way, ligation of TLR1/2 and TLR6/2 increased tumor cell survival in CLL by triggering NF- $\mathrm{kB}$ signaling [32].

Several B-cell lymphomas have been associated with viral or bacterial infections [47-50]. This led to the speculation that acute and sustained infections trigger malignant B-cell transformation via activation and induction of a prolonged proliferative state, favoring accumulation of genetic aberrations. The strongest 

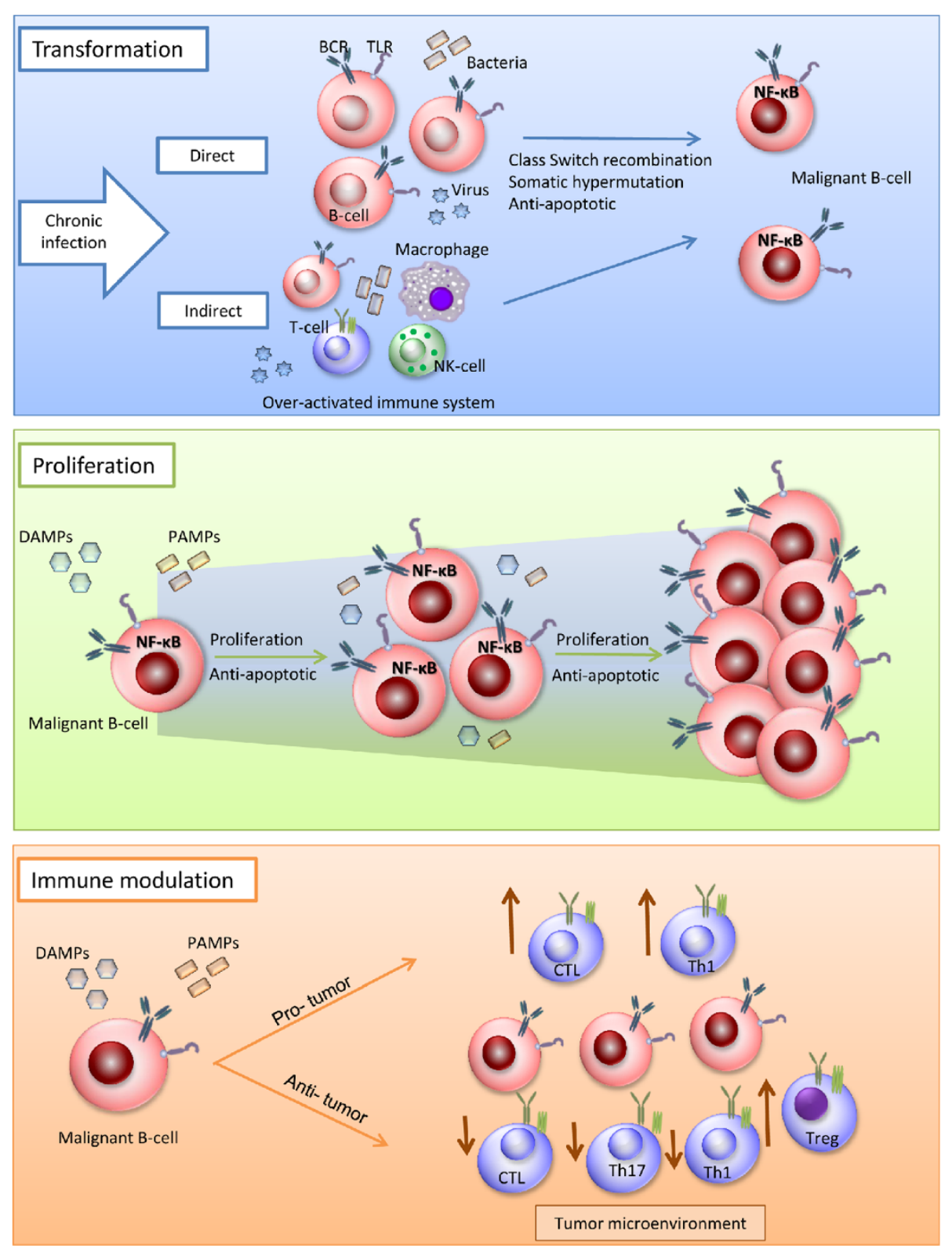

Figure 3 Possible roles of TLRs in the pathogenesis of human B-cell lymphomas. There are three possible mechanisms by which TLRs favor the pathogenesis of B cell malignancies. First, they can indirectly induce B-cell transformation by increasing the probability of mutations and double stranded DNA breaks after activation of naive B-cells or by favoring a pro-inflammatory microenvironment that increases the chance of mutations. Secondly, TLRs can direct the selection of a malignant clone by increasing proliferation and inhibiting apoptosis through the specific activation of NF-KB. Finally, malignant B-cell can modulate the immune response through stimulation of TLRs in two ways possibly depending on the cell type: The-pro tumor response favoring the increase of suppressor cells (like Tregs), and the decrease of a cytotoxic response (by downregulating Th1, Th17 and CTL) or an anti-tumor response by inreasing immunogenicity and increasing the sensitivity to CTLs and upregulating Th1.

evidence supporting this hypothesis is the regression and prolonged remission of gastric MALT lymphoma after treatment of Helicobacter (H.) pylori infections [51-53]. Interestingly, there is a correlation between infection and TLR expression pattern reported for specific lymphoma subtypes. MALT lymphomas express TLR4 [35] which recognizes LPS derived from Gram-negative bacteria like $H$. pylori [48]. BL and
DLBCL express TLR7, TLR8 and/or TLR9 [34,37], which mainly recognize single-stranded RNA or unmethylated CpG motifs from viruses. These lymphoma subtypes, although for DLBCL in only a small subpopulation of patients, have been associated with viruses like Epstein-Barr, Human immunodeficiency virus and HCV $[47,49,50]$. As TLRs have been shown to affect somatic hypermutation and class switch recombination 
$[15,18,19,21,27]$ it can be speculated that TLR triggering also facilitates non-Ig somatic aberrations that leads or contributes to the malignant transformation of germinal center B-cells.

In summary, the above mentioned studies provide evidence, although still mostly speculative and future analyses are required, for a possible role of TLRs in the malignant transformation via continuous TLR triggering following chronic infections or via induction of a cellular conditions that is prone to somatic mutations or DNA breaks.

\section{TLRs in proliferation of malignant B-cells and lymphoma progression}

Several studies showed induction of proliferation of malignant B-cells upon TLR triggering. Stimulation of TLR9 by CPG in 31 B-cell lymphoma samples strongly induced proliferation in CLL, revealed intermediate effects in MZL, CLL/SLL, FL and DLBCL and no effect in MCL and ALL [30,33]. ALL cells also did not respond to stimulation of TLR2 and TLR7 [33]. TLR4 triggering in MCL did show enhanced proliferation [36]. In CLL stimulation of TLR9 revealed more proliferation in unmutated compared to mutated $\operatorname{IgH}$ cases. Mutated cases showed a G1/S cell cycle arrest and increased number of apoptotic cells [54]. In MM cells, ligands for TLR1, TLR2, TLR4, TLR5, TLR6, TLR7 and TLR8 enhanced IL-6 dependent proliferation [8,28]. Activation of TLR7 and TLR9 protected MM cells from serum-deprivation or dexamethasone induced apoptosis [28]. One of the main contributors to the enhanced proliferation is probably achieved via the induction of NF- $\mathrm{kB}$, which also protects the cells from apoptosis (see above).

Together, these findings indicate that aberrant TLR activation in B-cell lymphoma may contribute to their proliferative potential and protect cells from apoptosis.

\section{TLRs in immune modulation}

TLRs have been proposed to contribute to the pathogenesis of B-cell malignancy as modulators of the immune system. Putative mechanisms involve modulation of pro- and anti- inflammatory cytokines and costimulatory molecules, induction of regulatory cells and alteration of T-cell function.

Triggering of TLR7 and/or TLR9 enhanced expression of co-stimulatory molecules, cytokines and/or chemokines in BL, CLL and ALL $[30,31,34,55,56]$. This indicates that the tumor cells become more immunogenic. Indeed, activation of TLR7 increases the sensitivity of CLL cells to cytotoxic T-cells [31,57]. LPS pre-treated primary MCL cells are able to resist killing by allogeneic cytotoxic T-cells by producing IL-10 and VEGF [36]. Triggering of ALL cells with the TLR9-ligand, failed to promote
T-cell proliferation by primary ALL cells, but turned the T-cell cytokine profile towards Th1 by upregulating IFN- $\gamma$ production of T-cells [57]. TLR2-stimulated ALL cell lines also enhanced expression of co-stimulatory markers and IFN- $\gamma$, but failed to induce T-cell proliferation [33]. In the normal B-cell response, enhancement of IL-6, IL-10, or IFN- $\gamma$ in response to TLR stimulation has been correlated to immunosuppressive functions. IL-10 production by B-cells after TLR4 or TLR9 triggering suppresses Th1 and Th17 cells [58] and after TLR2 stimulation induces IL-10 producing $\mathrm{T}$ regulatory (Treg) cells [59]. Patients with MM or lymphomas, such as FL, DLBCL and primary mediastinal B-cell lymphoma, frequently have high numbers of Treg cells in the microenvironment [60,61]. In addition, the in vivo and in vitro generation of Treg cells by B-cells was recently reported to be MyD88-dependent indicating another link with TLR stimulation [59].

Overall, there is clear evidence that supports a putative role of the TLRs in the modulation of the immune response and microenvironment in B-cell malignancies. The presence and activation of TLRs induces different mechanisms depending on the lymphoma subtype, the stimulated TLR and the microenvironment. TLR stimulation can favor proliferation of malignant B-cells by facilitating immune evasion through Treg induction and production of immunosuppressive cytokines. In contrast, in some situations, TLRs can stimulate resolution of the tumor by encouraging a cellular-mediated immune response.

\section{Therapeutic perspectives}

A main question to be addressed is: what are the effects of TLR agonists in vivo? In a mouse model for ALL, treatment with $\mathrm{CpG}$ oligonucleotides gave long term protection from ALL, by inducing a Th1 response $[62,63]$. Topical administration of Imiquimod, the ligand for TLR7, resolves skin manifestations in CLL patients and increased expression of co-stimulatory molecules on leukemic tumor cells [64]. A phase I study of TLR9 stimulation combined with rituximab in non-Hodgkin lymphoma showed no toxicity, induction of interferon and interferon inducible genes and an overall response rate of $32 \%(6 / 19)$ [65]. The phase II follow up study in relapsed and refractory FL patients, revealed enhanced antibody-dependent cell-mediated cytotoxicity in $11 / 23$ patients, and $74 \%$ of patients were alive without progressive disease at day 90 [66]. At least six clinical trials evaluating agonists for TLR3 (1 Trial), TLR7/8 (2 Trials) and TLR9 (3 Trials) in B non-Hodgkin lymphomas were in progress at January of 2008 [67]. Most of these have been terminated for different reasons, or the results have not been published yet. A phase I/II trial in CLL with a TLR7 agonist showed that part of the patients could be sensitized for vincristine [68], as had also been shown 
in vitro [69]. Notably, the effectiveness of several TLR agonists has been reported to be low in Phase III studies, so the number of research groups following this direction has decreased [67].

\section{Conclusion}

TLRs have been suggested as promoters of malignant transformation, tumor cell maintenance and progression in B-cell malignancies. The TLR expression patterns are diverse, not completely known yet for each B-cell malignancy, and could be normal for the B-cell phenotype or a consequence of transformation. TLR stimulation induced different effects in B-cell malignancies due to specific aberrations in the tumor cells or by differences in the tumor microenvironment. Despite these uncertainties, it is very likely that TLRs participate in the development and survival of malignant B cells.

There is a strong correlation between chronic infections and the development of some specific types of B-cell lymphoma. In these subtypes, it is likely that TLRs are directly involved in malignant transformation. In other B-cell malignancies, such as MM and CLL, TLRs appear to participate in immune evasion and tumor progression. It is evident that extreme precaution should be taken when considering the use of TLR agonists as (adjuvant) therapy in B-cell malignancies, because these agonists may have tumor-promoting properties.

\section{Competing interests}

The authors have no competing interests to disclose.

\section{Authors' contributions}

$J \mathrm{C}, \mathrm{ZL}$ and LV contributed to the literature analysis/interpretation and manuscript writing. AD, AvdB and LV edited/revised all drafts. All Authors approved the final version of the manuscript.

\section{Authors' information}

$J I C$ is a PhD student working on innate immunity. ZL is a PhD student, ENT physician and oncologist. AvdB is a molecular biologist working in lymphoma and non-coding RNA research. AD is a pathologist/scientist working in lymphoma and EBV-related research. LV is a scientist working in the field of lymphoma and tumor immunology.

Received: 3 June 2014 Accepted: 28 July 2014

Published: 12 August 2014

\section{References}

1. Akira S, Takeda K: Toll-like receptor signaling. Nat Rev Immunol 2004, 4:499-511.

2. Sato Y, Goto Y, Narita N, Hoon DS: Cancer cells expressing toll-like receptors and the tumor microenvironment. Cancer Microenviron 2009, 2(Suppl 1):205-214.

3. Li X, Jiang S, Tapping RI: Toll-like receptor signaling in cell proliferation and survival. Cytokine 2010, 49:1-9.

4. Chiron D, Bekeredjian-Ding I, Pellat-Deceunynck C, Bataille R, Jego G: Toll-like receptors: lessons to learn from normal and malignant human B cells. Blood 2008, 112:2205-2213.

5. Hornung V, Rothenfusser S, Britsch S, Krug A, Jahrsdörfer B, Giese T, Endres S, Hartmann G: Quantitative expression of toll-like receptor 1-10 mRNA in Cellular subsets of human peripheral blood mononuclear cells and sensitivity to CpG Oligodeoxynucleotides. J Immunol 2002, 168:4531-4537.

6. Bernasconi NL, Onai N, Lanzavecchia A: A role for Toll-like receptors in acquired immunity: up-regulation of TLR9 by BCR triggering in naive $B$ cells and constitutive expression in memory B cells. Blood 2003, 101:4500-4504.

7. Mansson A, Adner M, Hockerfelt U, Cardell LO: A distinct Toll-like receptor repertoire in human tonsillar B cells, directly activated by PamCSK, R-837 and CpG-2006 stimulation. J Immunol 2006, 118:539-548.

8. Bohnhorst J, Rasmussen T, Moen SH, Fløttum M, Knudsen L, Børset M, Espevik T, Sundan A: Toll-like receptors mediate proliferation and survival of multiple myeloma cells. Leukemia 2006, 20:1138-1144.

9. Bourke E, Bosisio D, Golay J, Polentarutti N, Mantovani A: The toll-like receptor repertoire of human $B$ lymphocytes: inducible and selective expression of TLR9 and TLR10 in normal and transformed cells. Blood 2003, 102:956-963.

10. Bekeredjian-Ding IB, Wagner M, Hornung V, Giese T, Schnurr M, Endres S, Hartmann G: Plasmacytoid dendritic cells control TLR7 sensitivity of naive B cells via type I IFN. J Immunol 2005, 174:4043-4050.

11. Agrawal S, Gupta S: TLR1/2, TLR7, and TLR9 signals directly activate human peripheral blood naïve and memory $B$ cell subsets to produce cytokines, chemokines and hematopoietic growth factors. J Clin Immunol 2011, 31:89-98.

12. Ganley-Leal LM, Liu X, Wetzler LM: Toll-like receptor 2-mediated human B cell differentiation. Clin Immunol 2006, 120:272-284.

13. Browne EP: Toll-like receptor 7 controls the anti-retroviral germinal center response. PLoS Pathog 2011, 7:e1002293.

14. Bessa J, Kopf M, Bachmann MF: IL-21 and TLR signaling regulate germinal center responses in a B cell-intrinsic manner. J Immunol 2010, 184:4615-4619.

15. Lutzker S, Rothman P, Pollock R, Coffman R, Alt FW: Mitogen- and IL-4-regulated expression of germ-line Ig gamma $2 \mathrm{~b}$ transcripts: evidence for directed heavy chain class switching. Cell 1988, 53:177-184.

16. Lin L, Gerth AJ, Peng SL: CpG DNA redirects class-switching towards "Th1-like" Ig isotype production via TLR9 and MYD88. Eur J Immunol 2004, 34:1483-1487.

17. Ruprecht CR, Lanzavecchia A: Toll-like receptor stimulation as a third signal required for activation of human naive B cells. Eur J Immunol 2006, 36:810-816.

18. He B, Qiao X, Cerutti A: CpG DNA induces IgG class switch DNA recombination by activating human $B$ cells through an innate pathway that requires TLR9 and cooperates with IL-10. J Immunol 2004, 173:4479-4491.

19. Xu W, Santini PA, Matthews AJ, Chiu A, Plebani A, He B, Chen K, Cerutti A: Viral double-stranded RNA triggers Ig class switching by activating upper respiratory mucosa $B$ cells through an innate TLR3 pathway involving BAFF. J Immunol 2008, 181:276-287

20. Jain S, Chodisetti SB, Agrewala JN: CD40 signaling synergizes with TLR-2 in the BCR independent activation of resting B cells. PLoS One 2011, 6:e20651.

21. Aranburu A, Ceccarelli S, Giorda E, Lasorella R, Ballatore G, Carsetti R: TLR ligation triggers somatic hypermutation in transitional $B$ cells inducing the generation of IgM memory B cells. J Immunol 2010, 185:7293-7301.

22. Pasare C, Medzhitov R: Control of B-cell responses by Toll-like receptors. Nature 2005, 438:364-368.

23. Kasturi SP, Skountzou I, Albrecht RA, Koutsonanos D, Hua T, Nakaya HI, Ravindran R, Stewart S, Alam M, Kwissa M, Villinger F, Murthy N, Steel J, Jacob J, Hogan RJ, Garcia-Sastre A, Compans R, Pulendran B: Programming the magnitude and persistence of antibody responses with innate immunity. Nature 2011, 470:543-550.

24. Eckl-Dorna J, Batista FD: BCR-mediated uptake of antigen linked to TLR9 ligand stimulates B-cell proliferation and antigen-specific plasma cell formation. Blood 2009, 113:3969-3977.

25. Hou B, Saudan P, Ott G, Wheeler ML, Li M, Kuzmich L, Lee LM, Coffman RL, Bachmann MF, DeFranco AL: Selective utilization of Toll-like receptor and MyD88 signaling in B cells for enhancement of the antiviral germinal center response. Immunity 2011, 34:375-384.

26. Jiang W, Lederman MM, Harding CV, Rodriguez B, Mohner RJ, Sieg SF: TLR9 stimulation drives naïve $B$ cells to proliferate and to attain enhanced antigen presentation. Eur J Immunol 2007, 37:2205-2213.

27. Capolunghi F, Cascioli S, Giorda E, Rosado MM, Plebani A, Auriti C, Seganti G, Zuntini R, Ferrari S, Cagliuso M, Quinti I, Carsetti R: CpG drives human transitional $B$ cells to terminal differentiation and production of natural antibodies. J Immunol 2008, 180:800-808.

28. Jego G, Bataille R, Geffroy-Luseau A, Descamps G, Pellat-Deceunynck C Pathogen-associated molecular patterns are growth and survival factors for human myeloma cells through Toll-like receptors. Leukemia 2006, 20:1130-1137. 
29. Xu Y, Zhao $Y$, Huang $H$, Chen $G$, Wu X, Wang $Y$, Chang $W$, Zhu Z, Feng $Y$, Wu D: Expression and function of toll-like receptors in multiple myeloma patients: toll-like receptor ligands promote multiple myeloma cell growth and survival via activation of nuclear factor-kappaB. Br J Haematol 2010, 150:543-553.

30. Jahrsdorfer B, Mühlenhoff L, Blackwell SE, Wagner M, Poeck H, Hartmann E, Jox R, Giese T, Emmerich B, Endres S, Weiner GJ, Hartmann G: B-cell lymphomas differ in their responsiveness to $\mathrm{CpG}$ oligodeoxynucleotides. Clin Cancer Res 2005, 11:1490-1499.

31. Spaner DE, Shi Y, White D, Mena J, Hammond C, Tomic J, He L, Tomai MA, Miller RL, Booth J, Radvanyi L: Immunomodulatory effects of Toll-like receptor-7 activation on chronic lymphocytic leukemia cells. Leukemia 2006 20:286-295.

32. Muzio M, Scielzo C, Bertilaccio MT, Frenquelli M, Ghia P, Caligaris-Cappio F: Expression and function of toll like receptors in chronic lymphocytic leukaemia cells. Br J Haematol 2008, 144:507-516.

33. Corthals SL, Wynne K, She K, Shimizu H, Curman D, Garbutt K, Reid GS: Differential immune effects mediated by Toll-like receptors stimulation in precursor B-cell acute lymphoblastic leukaemia. Br J Haematol 2005, 132:452-458.

34. Henault M, Lee LN, Evans GF, Zuckerman SH: The human Burkitt lymphoma cell line Namalwa represents a homogenous cell system characterized by high levels of Toll-like receptor 9 and activation by CpG oligonucleotides. J Immunol Methods 2005, 300:93-99.

35. Adam P, Schmausser B, Göbeler-Kolve M, Müller-Hermelink HK, Eck M: Gastric extranodal marginal zone B-cell lymphomas of MALT type exclusively express Toll-like receptor 4 in contrast to other lymphomas infiltrating the stomach. Ann Oncol 2008, 19:566-569.

36. Wang L, Zhao Y, Qian J, Sun L, Lu Y, Li H, Li Y, Yang J, Cai Z, Yi Q: Toll-like receptor-4 signaling in mantle cell lymphoma: Effects on tumor growth and immune evasion. Cancer 2013, 119:782-791.

37. Smith TJ, Yamamoto K, Kurata M, Yukimori A, Suzuki S, Umeda S, Sugawara E, Kojima Y, Sawabe M, Nakagawa Y, Suzuki K, Crawley JTB, Kitagawa M: Differential expression of Toll-like receptors in follicular lymphoma, diffuse large B-cell lymphoma and peripheral T-cell lymphoma. Exp Mol Pathol 2010, 89:284-290.

38. Purdue MP, Lan Q, Wang SS, Kricker A, Menashe I, Zheng TZ, Hartge P, Grulich AE, Zhang Y, Morton LM, Vajdic CM, Holford TR, Severson RK, Leaderer BP, Cerhan JR, Yeager M, Cozen W, Jacobs K, Davis S, Rothman N, Chanock SJ, Chatterjee N, Armstrong BK: A pooled investigation of Toll-like receptor gene variants and risk of non-Hodgkin lymphoma. Carcinogenesis 2009, 30:275-281.

39. Nieters A, Beckmann L, Deeg E, Becker N: Gene polymorphisms in Toll-like receptors, interleukin-10, and interleukin-10 receptor alpha and lymphoma risk. Gene Immun 2006, 7:615-624.

40. Mollaki V, Georgiadis T, Tassidou A, loannou M, Daniil Z, Koutsoukera A, Papathanassiou AP, Zintzaras E, Vassilopoulos G: Polymorphisms and haplotypes in TLR9 and MyD88 are associated with the development of Hodgkin's lymphoma: a candidate-gene association study. J Hum Genet 2009, 54:655-659.

41. Monroy CM, Cortes AC, Lopez MS, D'Amelio AM, Etzel CJ, Younes A, Strom SS, El-Zein RA: Hodgkin disease risk: role of genetic polymorphisms and gene-gene interactions in inflammatory pathway genes. Mol Carcinogen 2011, 50:36-46.

42. Ngo VN, Young RM, Schmitz R, Jhavar S, Xiao W, Lim KH, Kohlhammer H, Xu W, Yang Y, Zhao H, Shaffer AL, Romesser P, Wright G, Powell J, Rosenwald A, Muller-Hermelink HK, Ott G, Gascoyne RD, Connors JM, Rimsza LM, Campo E, Jaffe ES, Delabie J, Smeland EB, Fisher RI, Braziel RM, Tubbs RR, Cook JR, Weisenburger DD, Chan WC, Staudt LM: Oncogenically active MYD88 mutations in human lymphoma. Nature 2011, 470:115-119.

43. Treon SP, Xu L, Yang G, Zhou Y, Liu X, Cao Y, Sheehy P, Manning RJ, Patterson CJ, Tripsas C, Arcaini L, Pinkus GS, Rodig SJ, Sohani AR, Harris NL, Laramie JM, Skifter DA, Lincoln SE, Hunter ZR: MYD88 L265P somatic mutation in Waldenström's macoglobulinemia. N Engl J Med 2012, 367:826-833.

44. Yan Q, Huang Y, Watkins AJ, Kocialkowski S, Zeng N, Hamoudi RA, Isaacson PG, de Leval L, Wotherspoon A, Du MQ: BCR and TLR signaling pathways are recurrently targeted by genetic changes in splenic marginal zone lymphomas. Haematologica 2012, 97:595-598.

45. Puente XS, Pinyol M, Quesada V, Conde L, Ordonez GR, Villamor N, Escaramis G, Jares P, Bea S, Gonzales-Diaz M, Bassaganyas L, Baumann T,
Juan M, Lopez-Guerra M, Colomer D, Tubio JMC, Lopez C, Navarro A, Tornador C, Aymerich M, Rozman M, Hernandez JM, Puenta DA, Freije JMP, Velasco G, Gutierrex-Fernandez A, Costa D, Carrio A, Guijarro S, Enjuanes A, et al: Whole-genome sequencing identifies recurrent mutations in chronic lymphocytic leukaemia. Nature 2011, 475:101105.

46. Shaffer AL 3rd, Young RM, Staudt LM: Pathogenesis of human B cell lymphomas. Annu Rev Immunol 2012, 30:565-610.

47. Suarez $F$, Lortholary $O$, Hermine $O$, Lecuit $M$ : Infection-associated lymphomas derived from marginal zone $B$ cells: a model of antigen-driven lymphoproliferation. Blood 2006, 107:3034-3044.

48. Ferreri AJM, Ernberg I, Copie-Bergman C: Infectious agents and lymphoma development: molecular and clinical aspects. J Int Med 2009, 265:421-438.

49. Kaplan LD: HIV-associated lymphoma. Best Pract Res Clin Haematol 2012, 25:101-117.

50. Roschewski M, Wilson WH: EBV-associated lymphomas in adults. Best Pract Res Clin Hematol 2012, 25:75-89.

51. Neubauer A, Thiede C, Morgner A, Alpen B, Ritter M, Neubauer B, Wündisch T, Ehninger G, Stolte M, Bayerdörffer E: Cure of Helicobacter pylori infection and duration of remission of low-grade gastric mucosa-associated lymphoid tissue lymphoma. J Nat/ Cancer Inst 1997, 89:1350-1355.

52. Salam I, Durai D, Murphy JK, Sundaram B: Regression of primary high-grade gastric B-cell lymphoma following Helicobacter pylori eradication. Eur J Gastroenterol Hepatol 2001, 13:1375-1378.

53. Wotherspoon AC, Doglioni C, Diss TC, Pan L, Moschini A, de Boni M, Isaacson PG: Regression of primary low-grade B-cell gastric lymphoma of mucosa-associated lymphoid tissue type after eradication of Helicobacter pylori. Lancet 1993, 342:575-577.

54. Longo PG, Laurenti L, Gobessi S, Petlickovski A, Pelosi M, Chiusolo P, Sica S, Leone G, Efremov DG: The Akt signaling pathway determines the different proliferative capacity of chronic lymphocytic leukemia B-cells from patients with progressive and stable disease. Leukemia 2007, 21:110-120.

55. Decker T, Schneller F, Sparwasser T, Tretter T, Lipford GB, Wagner H, Peschel C: Immunostimulatory CpG-oligonucleotides cause proliferation, cytokine production, and an immunogenic phenotype in chronic lymphocytic leukemia B cells. Blood 2000, 95:999-1006.

56. Wolska A, Cebula-Obrzut B, Smolewski P, Robak T: Effects of Toll-like receptor 7 and Toll-like receptor 9 signaling stimulators and inhibitors on chronic lymphocytic leukemia cells ex vivo and their interactions with cladribine. Leuk Lymphoma 2013, 54:1268-1278.

57. Reid GSD, She K, Terrett L, Food MR, Trudeau JD, Schultz KR: CpG stimulation of precursor B-lineage acute lymphoblastic leukemia induces a distinct change in costimulatory molecule expression shifts allogeneic T cells toward a Th1 response. Blood 2005, 105:3641-3647.

58. Lampropoulou V, Hoehlig K, Roch T, Neves P, Calderon Gomez E, Sweenie CH, Hao Y, Freitas AA, Steinhoff U, Anderton SM, Fillatreau S: TLR-activated B cells suppress T cell mediated autoimmunity. J Immunol 2008, 180:4763-4773.

59. Sayi A, Kohler E, Toller IM, Flavell RA, Müller W, Roers A, Müller A: TLR-2-activated B cells suppress Helicobacter-induced preneoplastic gastric immunopathology by inducing T regulatory-1 cells. J Immunol 2011, 186:878-890

60. Brimnes MK, Vangsted AJ, Knudsen LM, Gimsing P, Gang AO, Johnsen HE, Svane IM: Increased level of both CD4 + FoxP3 + regulatory T cells and CD14 + HLA-DR-/low myeloid-derived suppressor cells and decreased level of dendritic cells in patients with multiple myeloma. Scand J Immunol 2010, 72:540-547.

61. Tzankov A, Meier C, Hirschmann P, Went P, Pileri SA, Dirnhofer S: Correlation of high numbers of intratumoral FoxP3+ regulatory $T$ cells with improved survival in germinal center-like diffuse large B-cell lymphoma, follicular lymphoma and classical Hodgkin's lymphoma. Hematologica 2008, 93:193-200.

62. Fujii H, Trudeau JD, Teachey DT, Fish JD, Grupp SA, Schultz KR, Reid GSD: In vivo control of acute lymphoblastic leukemia by immunostimulatory CpG oligonucleotides. Blood 2007, 109:2008-2013.

63. Seif AE, Barrett DM, Milone M, Brown VI, Grupp SA, Reid GSD: Long-term protection from syngeneic acute lymphoblastic leukemia by $\mathrm{CpG}$ ODN-mediated stimulation of innate and adaptive immune responses. Blood 2009, 114:2459-2466.

64. Spaner DE, Miller RL, Mena J, Grossman L, Sorrenti V, Shi Y: Regression of lymphomatous skin deposits in a chronic lymphocytic leukemia patient treated with the Toll-like receptor-7/8 agonist, imiquimod. Leuk Lymphoma 2005, 46:935-939. 
65. Friedberg JW, Kim H, McCauley M, Hessel EM, Sims P, Fisher DC, Nadler LM, Coffman RL, Freedman AS: Combination therapy with CpG oligonucleotide (1018 ISS) and rituximab in patients with non-Hodgkin lymphoma: increased interferon- $\alpha / \beta$-inducible gene expression, without significant toxicity. Blood 2005, 105:489-495.

66. Friedberg JW, Kelly JL, Neuberg D, Peterson DR, Kutok JL, Salloum R, Brenn T, Fisher DC, Ronan E, Dalton V, Rich L, Marquis D, Sims P, Rothberg PG, Liesveld J, Fisher RI, Coffman R, Mosmann T, Freedman AS: Phase II study of a TLR-9 agonist (1018 ISS) with rituximab in patients with relapsed or refractory follicular lymphoma. Br J Haematol 2009, 146:282-291.

67. Galluzzi L, Vacchelli E, Eggermont A, Fridman WH, Galon J, Sautès-Fridman C, Tartour E, Zitvogel L, Kroemer G: Trial Watch: Experimental Toll-like receptor agonists for cancer therapy. Oncoimmunology 2012, 1:699-716.

68. Spaner DE, Shi Y, White D, Shaha S, He L, Masellis A, Wong K, Gorczynski R: A phase I/II trial of TLR-7 agonist immunotherapy in chronic lymphocytic leukemia. Leukemia 2010, 24:222-226.

69. Shi Y, White D, He L, Miller RL, Spaner DE: Toll-like receptor-7 tolerizes malignant B cells and enhances killing by cytotoxic agents. Cancer Res 2007, 67:1823-1831.

doi:10.1186/s13045-014-0057-5

Cite this article as: Isaza-Correa et al:: Toll-like receptors in the pathogenesis of human B cell malignancies. Journal of Hematology \& Oncology 2014 7:57.

\section{Submit your next manuscript to BioMed Central and take full advantage of:}

- Convenient online submission

- Thorough peer review

- No space constraints or color figure charges

- Immediate publication on acceptance

- Inclusion in PubMed, CAS, Scopus and Google Scholar

- Research which is freely available for redistribution 